\title{
Thermal Characteristics of a Stratospheric Airship with Natural Convection and External Forced Convection
}

\author{
Tong Zhang $\mathbb{D},{ }^{1}$ Shanshan Geng, ${ }^{2}$ Xin $\mathrm{Mu}^{2}{ }^{2}$ Jiamin Chen, ${ }^{2}$ Junyi Wang, ${ }^{2}$ and Zan Wu ${ }^{2}$ \\ ${ }^{1}$ College of Aerospace Engineering, Nanjing University of Aeronautics and Astronautics, China \\ ${ }^{2}$ College of Energy and Power Engineering, Jiangsu University of Science and Technology, China \\ Correspondence should be addressed to Tong Zhang; lee4@nuaa.edu.cn
}

Received 9 March 2019; Revised 9 July 2019; Accepted 22 July 2019; Published 8 September 2019

Academic Editor: Paul Williams

Copyright (C) 2019 Tong Zhang et al. This is an open access article distributed under the Creative Commons Attribution License, which permits unrestricted use, distribution, and reproduction in any medium, provided the original work is properly cited.

\begin{abstract}
Though convective heat transfer is one of the main factors that dominate the thermal characteristics of stratospheric airships, there is no specific correlation equations for the calculation of convective heat transfer of airships. The equations based on flat plate and sphere models are all in use. To ameliorate the confusing situation of diverse convective heat transfer equations and to end the misuse of them in the thermal characteristic analysis of stratospheric airships, a multinode steady-state model for ellipsoid airships is built. The accuracy of the five widely accepted equations for natural convective heat transfer is compared and analysed on the proposed large-scale airship model by numerical simulation, so does that of the five equations for external forced convective heat transfer. The simulation method is verified by the available experimental data. Simulation results show that the difference of the five natural convection equations is negligible, while that of the five external forced convection equations must be considered in engineering. Forced convection equations with high precision and wide application should be further investigated.
\end{abstract}

\section{Introduction}

Stratospheric airships are the airships conducting missions at altitudes of $20-30 \mathrm{~km}$, which have a wide range of applications in military, scientific, and commercial areas, such as surveillance, intelligence and reconnaissance, aerial transportation, environmental monitoring, telecommunication relay, and emergency rescue [1-3]. In the late 1990s, the research and development of stratospheric airships began to thrive [2], and ever since then, great progress has been achieved in path-following control $[4,5]$, positioning control [6], and thermal performance analysis $[3,7,8]$. Nevertheless, the thermal characteristics of stratospheric airships remain challenging due to the complexity in heat transfer analysis. A stratospheric airship involves complicated convective heat transfer processes coupling with ambient thermal changes. Affected by the diurnal variation of solar radiation, the temperature distribution of airship envelope changes during a period of one day. Both external and internal surfaces of the envelope experience convective heat transfer, which accounts for a large proportion of the overall heat transfer of a stratospheric airship, thereby being the most important factors affecting the thermal characteristics of stratospheric airships. Therefore, it is crucial to investigate the convective heat transfer for accurately predicting the airship thermal characteristics. The heat convections inside and outside stratospheric airships are generally considered as natural and forced ones, respectively $[2,3]$. Since it seems intractable to obtain the convection heat transfer coefficient of the airship $h(h=\mathrm{Nu}(\lambda / L))$ via theoretical analysis, the coefficient is usually acquired in engineering by diverse empirical and semiempirical $\mathrm{Nu}$ correlation equations based on experiments. There is no specific correlation for $\mathrm{Nu}$ yet, and correlation equations for flat plates and spheres are all in use [2]. The direct adoption of these equations in thermal characteristic analysis of stratospheric airships will cause some uncertainties if their feasibility for large ellipsoid shapes under the working conditions of the airships is not considered. 


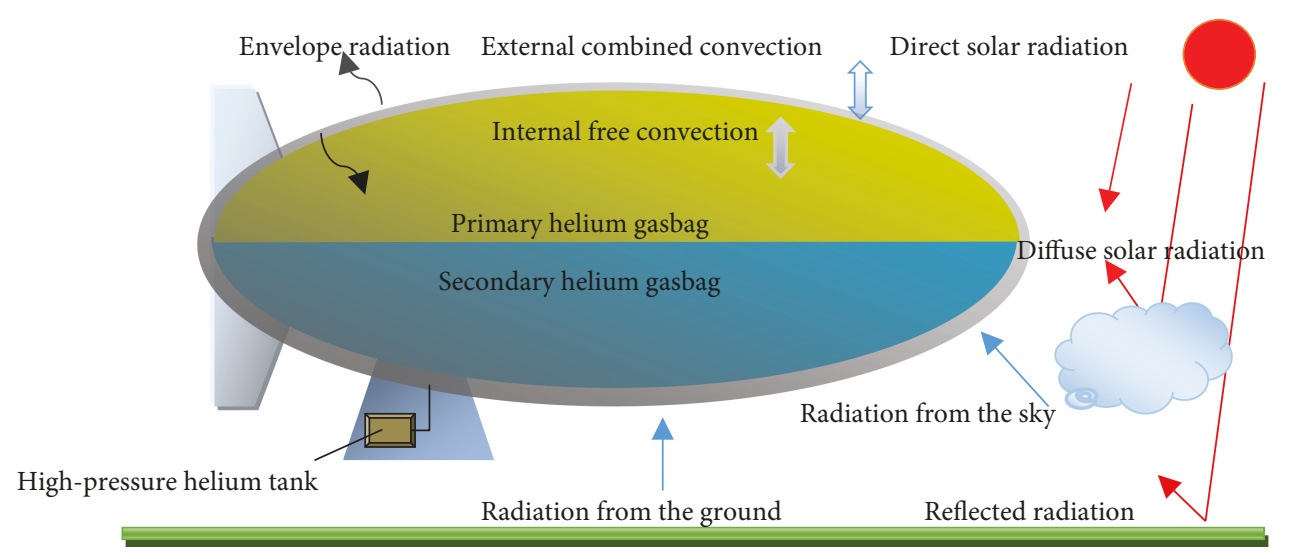

FIGURE 1: Schematic diagram of the thermal environment of an airship.

The $\mathrm{Nu}$ correlation equations for natural convection are mostly based on geometric models of horizontal and vertical plates, presented by scholars in the field of architecture. Eckert and Jackson [9], Bayley [10], and Clark [11] proposed the widely used correlation equations for natural convection in the form of $\mathrm{Nu}=\mathrm{CRa}^{n}$ with different $C$ factors in 1950, 1955, and 1969, respectively. Rohsenow [12] provided an equation regarding $\mathrm{Nu}$ to the spatial position of airship envelope by using the concept of grid discretisation. Some scholars, such as Carlson and Horn [13] and Morris [14], introduced the correlation equations for natural convection in the shell. However, until now few correlation equations have been reported to accurately calculate the natural convection inside large spheres or ellipsoids.

Carlson and Horn [13] and Incropera and De Witt [15] proposed the correlation equations for external forced convection of spheres in 1983 and 1996, respectively, while Holman [16], Morris [14], and Kreith [17] presented the equations for external forced convection of horizontal plate. Until 2011, Kishore and $\mathrm{Gu}$ [18] and Richter and Nikrityuk [19] proposed the equations for ellipsoid external forced convection at small Reynolds numbers (lower than $10^{5}$ ). In 2013, Dai et al. [20] investigated the correlation equation for external forced convection of spheres at high Reynolds numbers $\left(\operatorname{Re}=10^{6}, 10^{8}\right)$ via numerical simulation and modified it in order to apply to ellipsoid shapes in 2016 [21].

All the aforementioned works focus on the presentation and modification of correlation equations, while the comparison of applicable ranges of these correlation equations, for instance, geometry and fluid characteristics, is hardly addressed. Since each correlation equation is valid for a specific configuration with limitations on the range of parameters based on experimentally determined data, they do not always provide accurate predictions of $h$. Errors as high as $25 \%$ are not uncommon [22]. Hence, to ameliorate the confusing situation of diverse convective heat transfer equations and to end the misuse of them in the thermal characteristic analysis of stratospheric airships, an ellipsoid airship model is built herein, and the accuracy of ten widely accepted equations for convective heat transfer is compared and analysed on the proposed large-scale airship model by numerical simulation. The simulation method is verified using the available experimental data. This study provides reference for the selection and correction of convective heat transfer equations.

\section{Thermal Model}

When hovering in the air, an airship is typically composed of a primary helium gasbag, a secondary helium gasbag, and a high-pressure helium tank, as shown in Figure 1. The primary gasbag is hermetic, and its mass remains constant while its volume changes with the intensity of solar radiation. To keep the airship at a fixed point, the high-pressure tank regulates the volume and pressure of the airship via helium inducting and exhausting [23]. Put differently, when the temperature and volume of the primary gasbag increase, gas in the secondary gasbag will be compressed into the highpressure tank; when the temperature of the primary helium gasbag drops, helium is released from the tank to the secondary helium gasbag.

The ellipsoidal stratospheric airship has a major axis of $110 \mathrm{~m}$ and a slenderness ratio of 4 . The solar absorption and emissivity factor of the envelope are 0.38 and 0.8 , respectively. The airship is exposed to direct and diffuse solar radiation, reflected radiation, long-wave radiation from the sky and ground, internal natural convection heat transfer, and external forced convection heat transfer. A schematic diagram of the thermal environment of the airship is shown in Figure 1.

The airship floats at an altitude of $20 \mathrm{~km}$. Facing east, the ship is blown by easterly wind at a speed of $12 \mathrm{~m} / \mathrm{s}$ with $\mathrm{Re}=3.67 \times 10^{6}$. It is assumed that the heat transfer outside the envelope is a forced convective one. After having gained energy from solar radiation, the envelope surface exhibits a temperature distribution that changes with position and time. Unevenly heated by the envelope, the helium in the airship naturally convects under the action of gravity and buoyancy. The Nusselt number for the convective heat transfer can be calculated by an empirical equation. However, the available equations are based on flat, spherical, or cylindrical models. To investigate the feasibility of these equations in calculating the thermal characteristics of ellipsoidal airships, we select ten generally accepted 
TABLE 1: Empirical equations for natural convection heat transfer.

\begin{tabular}{|c|c|c|c|}
\hline Proposed by & Geometry model & Empirical equation & \\
\hline Eckert and Jackson [9] & Vertical flat panel & $\mathrm{Nu}=0.021 \mathrm{Ra}^{2 / 5}, 10^{10} \leq \mathrm{Ra} \leq 10^{12}$ & (i) \\
\hline Bayley [10] & Vertical flat panel & $\mathrm{Nu}=0.1 \mathrm{Ra}^{1 / 3}, 10^{9} \leq \mathrm{Ra} \leq 10^{12}$ & (ii) \\
\hline Clark [11] & Horizontal flat panel & $\mathrm{Nu}=\left\{\begin{array}{l}0.59 \mathrm{Ra}^{1 / 4}, \text { laminar flow, } 10^{4} \leq \mathrm{Ra} \leq 10^{9}, \\
0.13 \mathrm{Ra}^{1 / 3}, \text { turbulent flow, } 10^{9}<\mathrm{Ra} \leq 10^{12}\end{array}\right.$ & (iii) \\
\hline Carlson and Horn [13] & Interior of sphere & $\mathrm{Nu}=\left\{\begin{array}{l}2.5\left(2+0.6 \mathrm{Ra}^{1 / 4}\right), \mathrm{Ra} \leq 1.5 \times 10^{8} \\
0.325 \mathrm{Ra}^{1 / 3}, \mathrm{Ra}>1.5 \times 10^{8}\end{array}\right.$ & (iv) \\
\hline Rohsenow [12] & Horizontal flat panel & $\mathrm{Nu}=\frac{2.8}{\ln \left(1+2.8 /\left[0.515(\mathrm{Ra} \cos \theta)^{1 / 4}\right]\right)}$ & (v) \\
\hline
\end{tabular}

TABLE 2: Empirical equations for forced convection heat transfer.

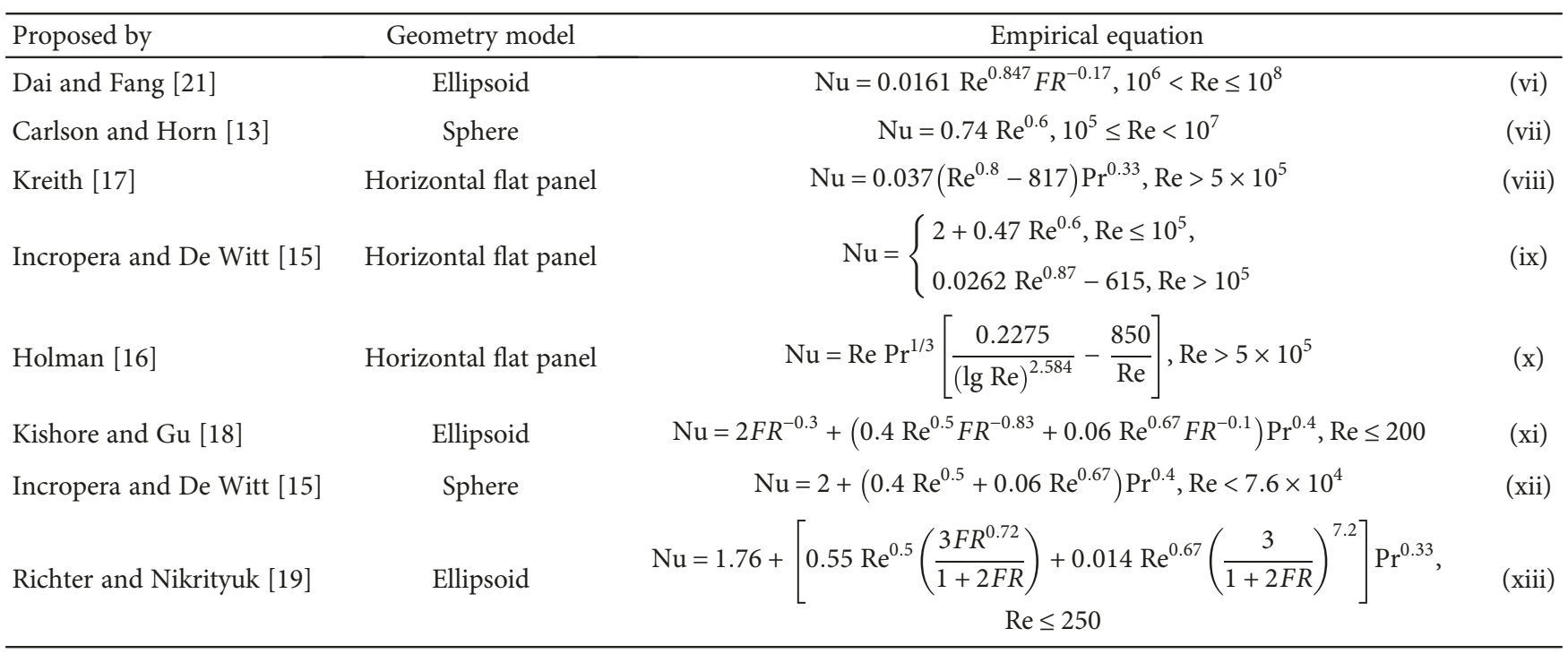

correlation equations, five for natural convective heat transfer and five for forced one. We then compare the calculation results of the envelope and helium temperatures using these equations with identical computational parameters.

The correlation equations for calculating the heat transfer of natural convection of the stratospheric airship are listed in Table 1.

The equations in Table 1 are all based on a simplified heat transfer model, such as sphere, horizontal flat panel, or vertical flat panel. Detailed information about the five equations for natural convection are as follows. Kreith and Kreider [24] suggested that the natural convection heat transfer model for a vertical flat panel, proposed by Eckert and Jackson [9], can be employed to compute the thermal characteristics of natural convection inside a balloon. The accuracy of the Bayley [10] model was proved by Warner and Arpaci [25] in natural air convection experiments on vertical flat panels. Clark [11] proposed a general form of a heat transfer equation for natural convection. Since natural convection is turbulent in most cases, only the turbulent part of the equation is used, for instance, in the computation of natural convection heat transfer inside aerostats by Farley [26] and Li et al. [27]. Carlson and Horn [13] provided a natural convection equation when studying the thermal characteristics of internal gas in balloons, which was used by Shi et al. [3] to calculate the heat transfer of internal natural convection of stratospheric airships. Rohsenow's [12] heat transfer equation for natural convection was used by Xia et al. [28] to study the transient thermal characteristics of aerostats. Concerning ellipsoidal airships, few studies can be referred to. It is worth mentioning that Zhang et al. [29] evaluated the aforementioned equations for natural convection using regression analysis and recommended that the equations proposed by Eckert and Jackson [9] and Bayley [10] are preferred for the internal natural convection of aerostats. However, Zhang based the recommendation on the computation of a given airship geometry and did not address the influences of the two recommended equations on the thermal characteristics of airships.

The typical Re range for a stratospheric airship is $20-10^{8}$, and the Nu range is $5-10^{5}$. Though there are many equations for the computation of external forced convection, most do not fall into the Re range above $10^{5}$. Table 2 lists eight empirical forced convection equations.

External forced convection heat transfer has been a focus in the field of heat transfer for decades. Experiments on 
simple geometries (flat panels, cylinders, and spheres) began in the early 20 th century. Though experimental investigations dominate the research of forced convection heat transfer on external spherical surfaces, more numerical analyses are reported with the advent and development of technologies in computational fluid dynamics (CFD) and computational heat transfer. The empirical equations for external forced convection are mainly proposed by Carlson and Horn [13] and Whitaker [30]. Reference [3] suggested that in the case of $\operatorname{Re}<7 \times 10^{5}$, Whitaker's formula is preferred in the external forced convection of spheres thanks to its calculation accuracy. Dai and Fang [21] conducted a regression analysis on forced convection heat transfer of an ellipsoid-based on the results of CFD using empirical equations proposed by Kishore and $\mathrm{Gu}$ [18] - and obtained an empirical equation of external forced convection for ellipsoid airships. Kreith [17] and Holman [16] studied the flow characteristics of stratospheric airships using a correlation on a flat panel. However, research results on correlation equations for ellipsoids have been limited due to complexity. Kishore and Richter proposed an external forced convection correlation of an ellipsoid in 2011 and 2012, respectively.

Herein, only the first five equations in Table 2 were simulated and analysed considering the specific conditions involved by stratospheric airships, such as Re.

\section{Governing Equations and Discretisation}

3.1. Governing Equations. Before the analysis of thermal characteristics, the following assumptions are made:

(1) The envelope temperature in the thickness direction is uniform

(2) Heat transfer of the envelope exists only in the thickness direction

(3) Phase change does not occur in the gas inside the airship

(4) Helium is regarded as the ideal gas

(5) Regardless of the leakage of the envelope, the helium only flows through the valve

(6) The temperature and pressure of helium in gasbags are uniformly distributed

(7) The envelope is opaque and solar radiation cannot penetrate

Therefore, the thermal equilibrium equation for the envelope unit of the airship is

$$
\begin{aligned}
\frac{m_{\mathrm{s}} c\left(d T_{i}\right)}{d t} & =q_{\mathrm{D}, i}+q_{\mathrm{S}, i}+q_{\mathrm{R}, i}+q_{\mathrm{IRS}, i}+q_{\mathrm{IRG}, i}-q_{\mathrm{IRE}, i}-q_{\mathrm{CE}, i} \\
& -q_{\mathrm{CI}, i}=\alpha_{\mathrm{e}} I_{\mathrm{DN}} \cos \left(\pi-\beta_{i}\right)+\alpha_{\mathrm{e}} I_{\mathrm{S}} X_{i, \mathrm{~s}}+\alpha_{\mathrm{e}} I_{\mathrm{R}} X_{i, \mathrm{~g}} \\
& +\varepsilon_{\mathrm{s}} \sigma T_{\mathrm{a}}^{4} X_{i, \mathrm{~s}}+\varepsilon \varepsilon_{\mathrm{g}} \sigma T_{\mathrm{g}}^{4} X_{i, \mathrm{~g}} \tau+\varepsilon \sigma T_{i}^{4} \\
& +h_{\mathrm{CE}}\left(T_{i}-T_{\mathrm{air}}\right)+h_{\mathrm{CI}}\left(T_{i}-T_{\mathrm{He}}\right) .
\end{aligned}
$$

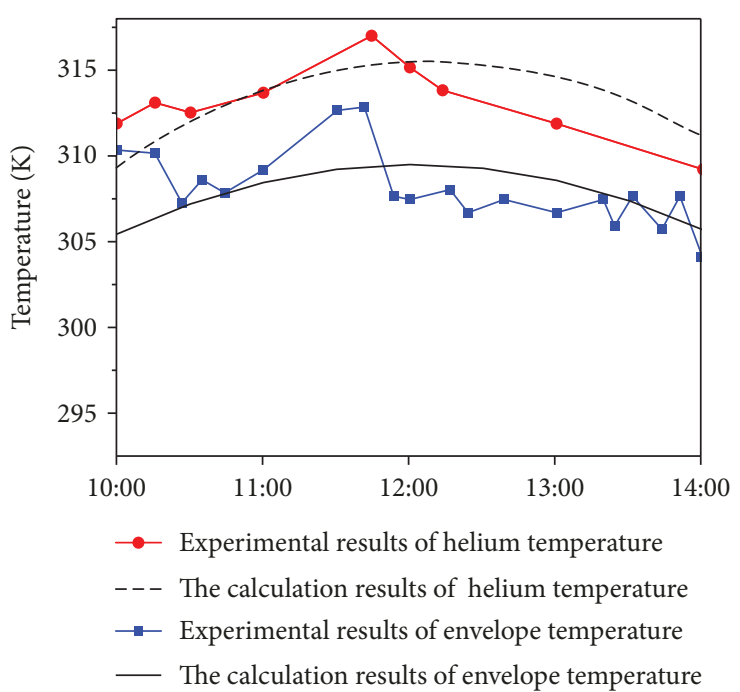

FIGURE 2: Comparison of the calculation and experiment results.

With assumptions 3 and 4 , the heat transfer of the helium gasbag can be described by the energy conservation equation of an open system.

The heat balance equation for the primary helium gasbag is

$$
\begin{aligned}
m_{1} c_{1} \frac{d T_{\mathrm{He} 1}}{d t} & =-\sum Q_{\mathrm{CI} 1}+Q_{12}-P \frac{d V_{1}}{d t}, \\
Q_{12} & =\frac{A\left(T_{\mathrm{He} 1}-T_{\mathrm{He} 2}\right)}{\left(1 / h_{\mathrm{CI} 1}\right)+(x / \lambda)+\left(1 / h_{\mathrm{CI} 2}\right)} .
\end{aligned}
$$

The heat balance equation for the secondary helium gasbag is

$$
m_{2} c_{2} \frac{d T_{\mathrm{He} 2}}{d t}=-\sum Q_{\mathrm{CI} 2}+Q_{21}+R_{\mathrm{g}, \mathrm{He}} T_{2} \frac{d m_{2}}{d t}-P \frac{d V_{2}}{d t},
$$

where $R_{\mathrm{g}, \mathrm{He}} T_{2}\left(d m_{2} / d t\right)$ is the energy carried by inducted and exhausted helium and $P \cdot d V_{2} / d t$ is the work done by the gas in the gasbags.

The total volume of the airship remains unchanged when hovering, i.e., $V_{\text {airship }}=V_{1}+V_{2}=$ const. The primary helium gasbag exchanges no mass with the outside. The auxiliary airbag is connected to the overpressure helium tank, and the internal and external pressure difference of the airship is constant through helium inducting and exhausting.

3.2. Discretisation. The envelope is discretised into sixty triangular elements (thirty nodes each for the upper and lower sections) using the finite element method to obtain accurate results. Thermal radiation and convection are iteratively looped as separate blocks. The thermal balance of each envelope unit and gasbag is analysed separately. The differential equations are solved by the Runge-Kutta method programmed in the $\mathrm{C}++$ language. 


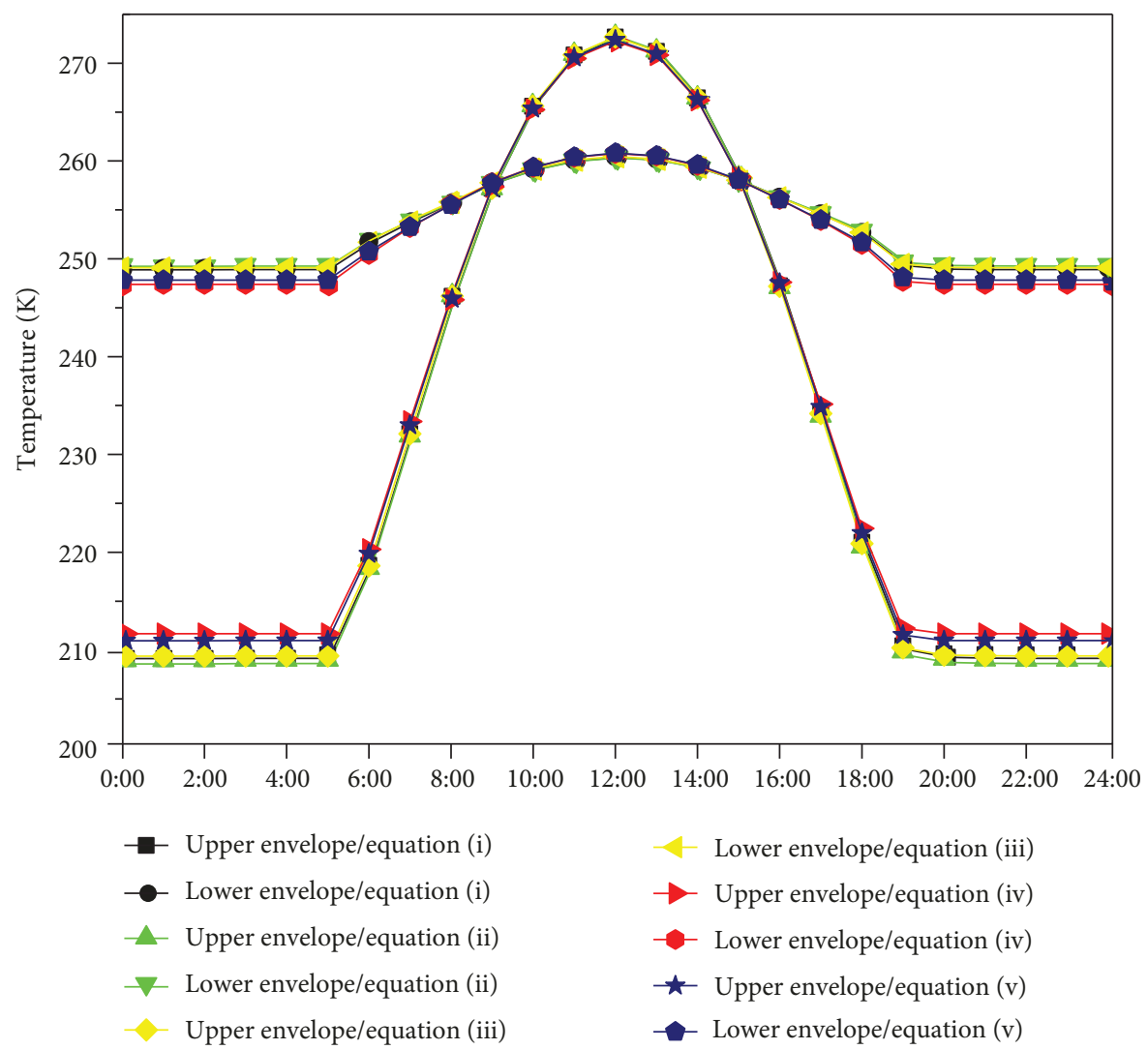

FIGURE 3: Envelope temperatures calculated by different natural convection equations.

\section{Verification of Program}

To verify the reliability of our $\mathrm{C}++$ program, we first used it to model the experiment in reference [31] - all parameters were set identically. The airship was $35 \mathrm{~m}$ long, equipped with solar panels, and composed of an upper helium gasbag and lower airbag. The material of the envelope had an absorption rate of 0.3 and emissivity of 0.8 . The time was chosen as the summer solstice (June 21) and the latitude as $36^{\circ} \mathrm{N}$. Subsequently, the calculation results were compared with the experimental ones. Figure 2 shows the comparison of calculation and experimental results.

In Figure 2, the overall trend of the calculation results concurs with that of the experiment. It shows that the helium temperature is higher than the average temperature of all envelope nodes. Before 12:00, the calculation and experimental results agree well with each other. After $12 \mathrm{~h}$, the latter are slightly lower than the former with a difference of less than $3 \mathrm{~K}$. The probable reason is that the effects of several parameters were not considered when programming, such as wind speed, wind direction change, and solar panel energy gain.

In short, the calculation error in this study is no more than $3 \mathrm{~K}$ compared with the experimental data, which can be neglected. Hence, our computational method and program is reliable.

\section{Simulation Results and Discussion}

5.1. Results of Natural Convection. Figures 3-5 show the calculation results of different equations for natural convection. We can see that in the daytime (from 5:00 to 19:00) the results of equations (i), (ii), (iii), (iv), and (v) are almost identical, indicating that the influence of selection of natural convection equations on envelope temperature is much smaller than that of solar radiation. Note that the envelope temperature differs at night because of the selection of natural convection equations. The results of equations (i), (ii), and (iii), which are all based on flat panel models, are similar because the difference of their convective heat transfer coefficients is negligible, being 0.2 approximately. The results of equations (iv) and (v) are close. Though equation (v) is also based on a flat panel model, it calculates each small discrete unit, thereby attaining results different from the model that simplifies the whole ellipsoid as a flat panel.

At any given moment of the day, the maximum difference in envelope temperature calculated by equations (i), (ii), (iii), (iv), and (v) is $2.7 \mathrm{~K}$, and the one in helium temperature is $4 \mathrm{~K}$. Equation ( $\mathrm{v}$ ) considers the influence of the spatial position of the envelope unit, and its calculation process is more complicated. The calculated result of equation (v) is close to that of the equation for natural convection inside a sphere. Temperature changes in the helium and envelope engender density changes in the helium in the gasbag. 


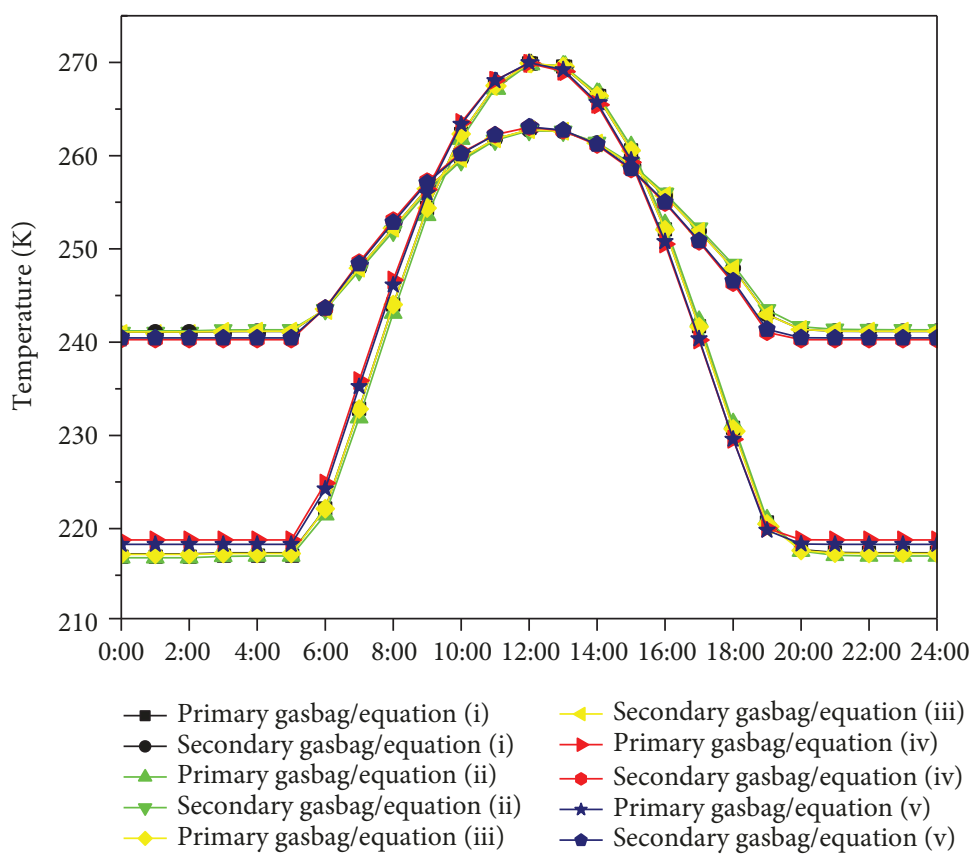

FIGURE 4: Helium gasbag temperatures calculated by different natural convection equations.

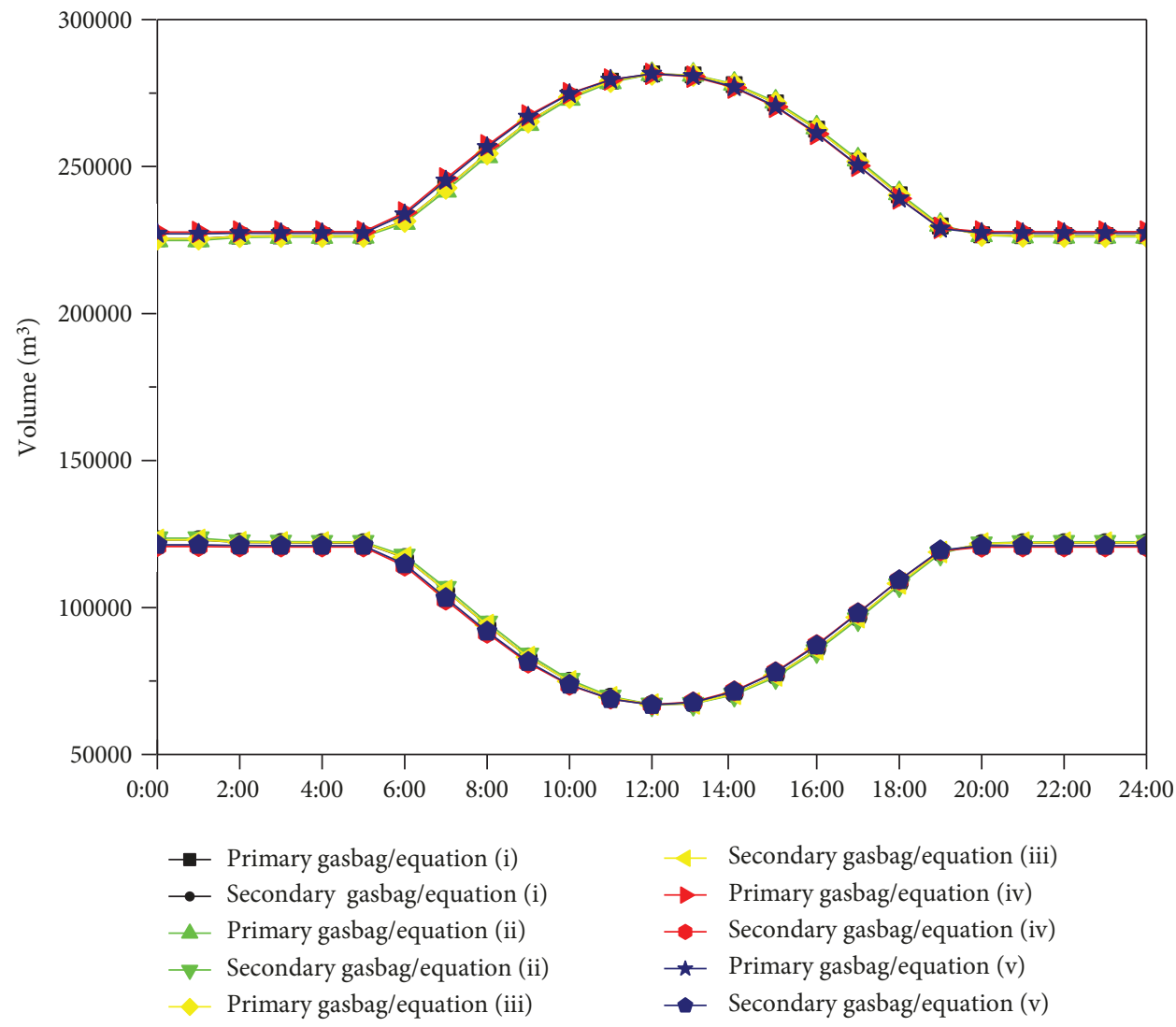

FIGURE 5: Helium gasbag volume changes calculated by different natural convection equations.

Differences due to the selection of natural convection equations can also be expressed in terms of gasbag volume. For an airship with a volume of $350,000 \mathrm{~m}^{3}$ approximately, the calculated differences between equations account for $0.057 \%$ and $0.8 \%$ of the total volume in the day and night with a time difference of 12 hours, respectively. 


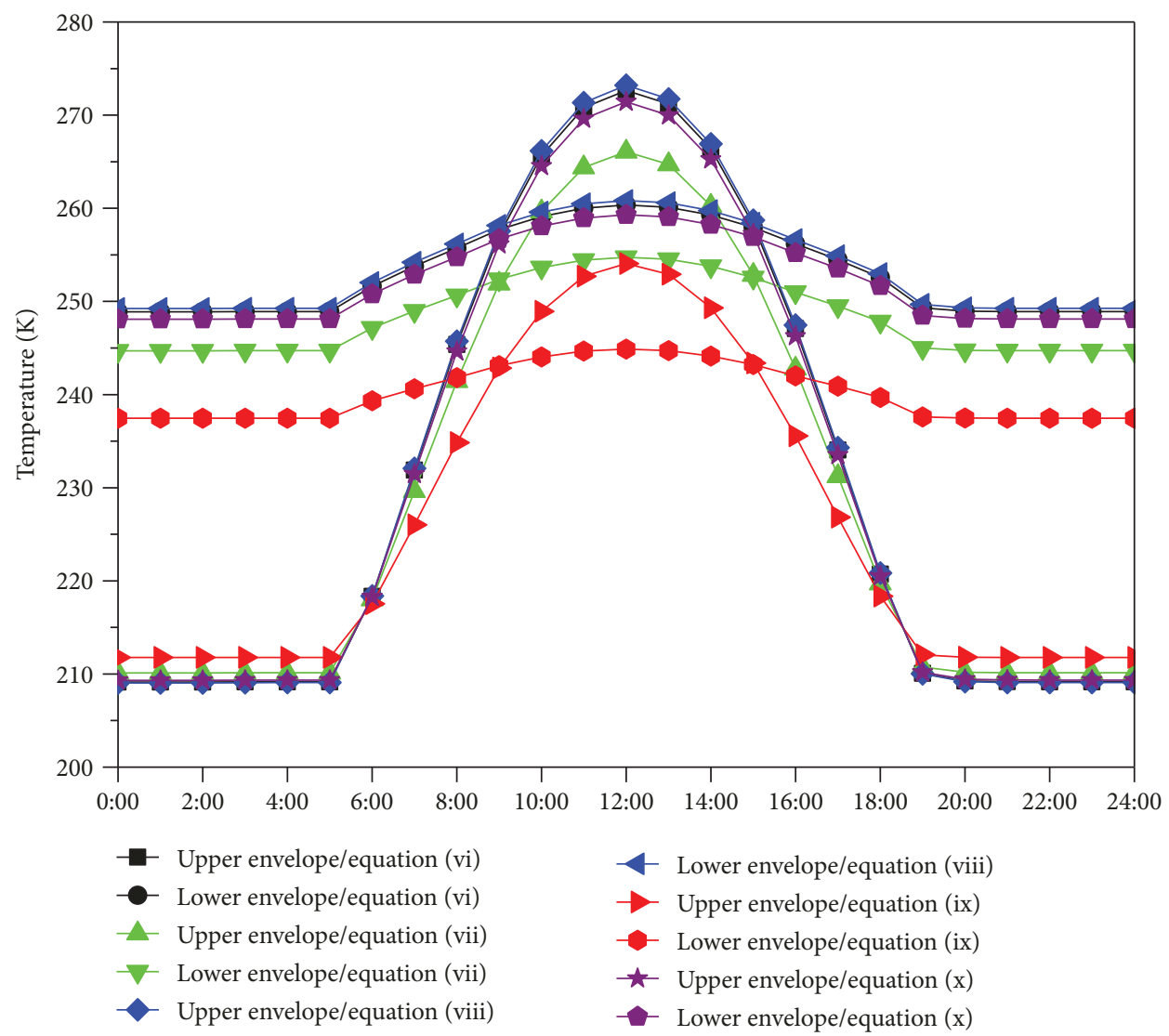

FIGURE 6: Envelope temperatures calculated by different forced convection equations.

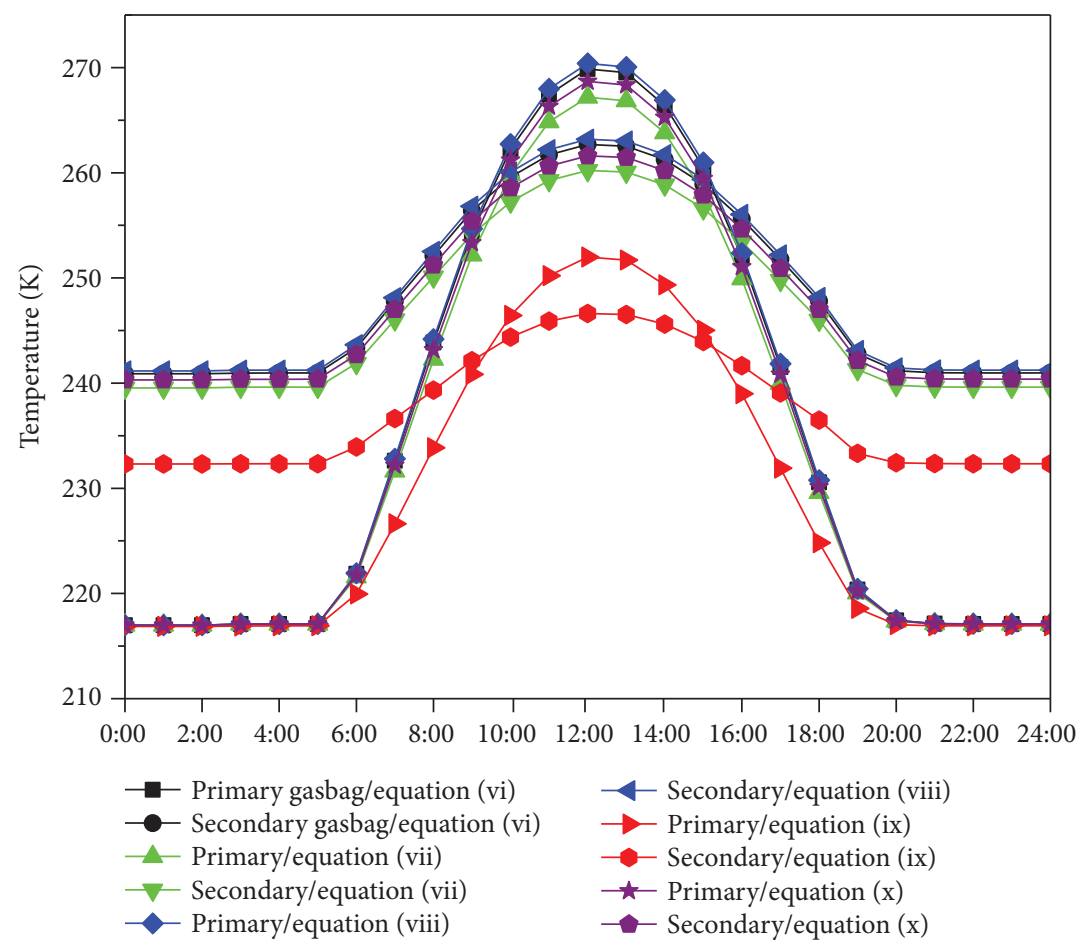

Figure 7: Helium bag temperatures calculated by different forced convection equations. 


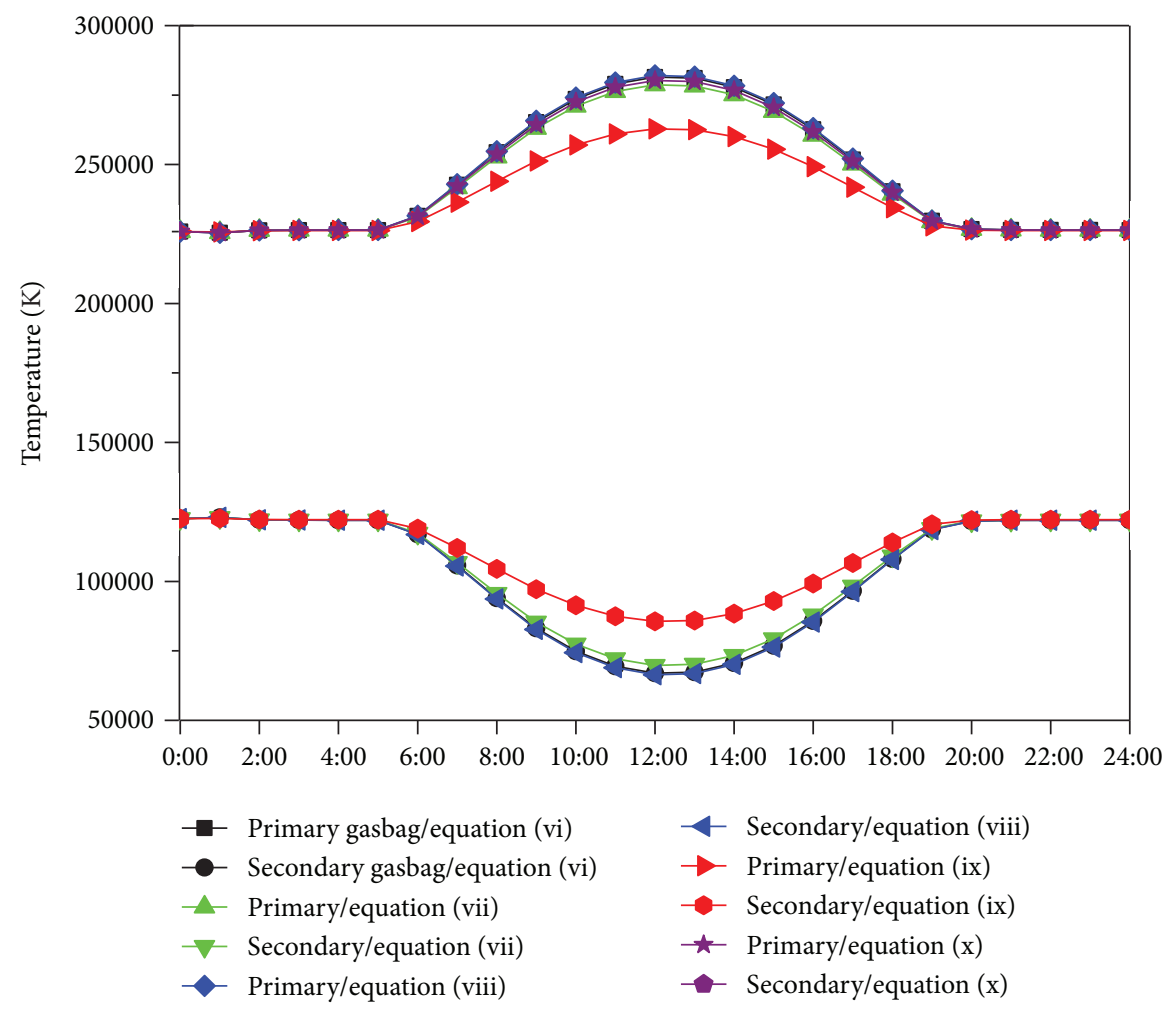

Figure 8: Helium gasbag volume changes calculated by different forced convection equations.

TABLE 3: Heat flux of the upper envelope calculated by different forced convection equations.

\begin{tabular}{lccccccccc}
\hline Equation & Time & $q_{\mathrm{D}, i}$ & $q_{\mathrm{S}, i}$ & $q_{\mathrm{R}, i}$ & $q_{\mathrm{IRS}, i}$ & $q_{\mathrm{IRG}, i}$ & $q_{\mathrm{IRE}, i}$ & $q_{\mathrm{CE}, i}$ & $q_{\mathrm{CI}, i}$ \\
\hline & $5: 00$ & 0 & 0 & 0 & 20.09 & 45.34 & 86.68 & -7.50 & -13.75 \\
& $8: 00$ & 112.92 & 39.07 & 3.89 & 20.09 & 45.34 & 166.23 & 1.21 & 52.76 \\
Equation (viii) & $12: 00$ & 242.70 & 43.76 & 7.47 & 20.09 & 45.34 & 253.93 & 2.78 & 102.64 \\
& $16: 00$ & 112.86 & 39.07 & 3.89 & 20.09 & 45.34 & 170.91 & -4.53 & 55.91 \\
& $19: 00$ & 0 & 0 & 0 & 20.09 & 45.34 & 88.27 & -10.62 & -12.03 \\
\hline \multirow{3}{*}{ Equation (ix) } & $5: 00$ & 0 & 0 & 0 & 20.09 & 45.34 & 91.26 & -4.00 & -21.82 \\
& $8: 00$ & 112.92 & 39.07 & 3.89 & 20.09 & 45.34 & 138.32 & 0.71 & 81.54 \\
& $12: 00$ & 242.70 & 43.76 & 7.47 & 20.09 & 45.34 & 189.58 & 2.00 & 167.78 \\
& $16: 00$ & 112.86 & 39.07 & 3.89 & 20.09 & 45.34 & 140.05 & -2.91 & 84.82 \\
& $19: 00$ & 0 & 0 & 0 & 20.09 & 45.34 & 91.71 & -5.56 & -20.65 \\
\hline
\end{tabular}

TABLE 4: Heat flux of the lower envelope calculated by different forced convection equations.

\begin{tabular}{lccccccccc}
\hline Equation & Time & $q_{\mathrm{D}, i}$ & $q_{\mathrm{S}, i}$ & $q_{\mathrm{R}, i}$ & $q_{\mathrm{IRS}, i}$ & $q_{\mathrm{IRG}, i}$ & $q_{\mathrm{IRE}, i}$ & $q_{\mathrm{CE}, i}$ & $q_{\mathrm{CI}, i}$ \\
\hline & $5: 00$ & 0 & 0 & 0 & 3.83 & 237.71 & 175.11 & 7.24 & 59.19 \\
& $8: 00$ & 0 & 7.45 & 20.38 & 3.83 & 237.71 & 195.30 & 2.18 & 71.70 \\
Equation (viii) & $12: 00$ & 0 & 8.35 & 39.18 & 3.83 & 237.71 & 209.97 & -1.10 & 80.19 \\
& $16: 00$ & 0 & 7.45 & 20.38 & 3.83 & 237.71 & 196.75 & 0.23 & 72.56 \\
& $19: 00$ & 0 & 0 & 0 & 3.83 & 237.71 & 176.27 & 5.40 & 59.94 \\
\hline \multirow{3}{*}{ Equation (ix) } & $5: 00$ & 0 & 0 & 0 & 3.83 & 237.71 & 144.24 & 3.91 & 93.38 \\
& $8: 00$ & 0 & 7.45 & 20.38 & 3.83 & 237.71 & 155.08 & 1.33 & 112.85 \\
& $12: 00$ & 0 & 8.35 & 39.18 & 3.83 & 237.71 & 163.15 & -0.77 & 126.69 \\
& $16: 00$ & 0 & 7.45 & 20.38 & 3.83 & 237.71 & 155.60 & 0.13 & 113.76 \\
& $19: 00$ & 0 & 0 & 0 & 3.83 & 237.71 & 144.57 & 3.03 & 93.98 \\
\hline
\end{tabular}


5.2. Results of Forced Convection. Figures 6-8 show the calculation results of the different forced convection equations. The external forced convection of the airship is more intense than the internal natural convection heat transfer, and the calculation results of the different equations are quite different. The calculation results of equations (vi), (viii), and (x) are relatively close. The maximum difference of helium at the same moment is approximately $2 \mathrm{~K}$, and the volume difference is approximately $1,800 \mathrm{~m}^{3}$. The envelope and helium temperatures calculated by equation (ix) are the minimum, with a maximum difference of $19 \mathrm{~K}$ from equations (vi), (vii), and (viii) and maximum volume difference of $19,000 \mathrm{~m}^{3}$. Equation (vi) is the calculation equation obtained by Dai, considering the relationship between $\mathrm{Nu}, \mathrm{Re}$, and slenderness ratio. The calculation results approach those of equation (viii) based on the flat panel model.

As shown in Figures 6-8, the calculation results of equations (viii) and (ix) differ most. Tables 3 and 4 show the heat flux of the envelope surface calculated by external forced convection equations (viii) and (ix). It can be seen that the dominant influence on upper envelope temperature is solar radiation. The enhancement of external convective heat transfer causes the night temperature of the upper envelope to rise and the daytime temperature to decrease.

Comparatively, solar radiation is not the dominant factor that influences the lower envelope temperature. In this case, the heat transfer of external convection accounts for a larger proportion of the total, thereby enhancing the temperature of lower envelope during the day and night. At 12:00, the calculated external convective heat fluxes of the upper envelope by equations (viii) and (ix) have a difference of $65 \mathrm{~W} / \mathrm{m}^{2}$; when calculated those of the lower envelope, the difference was $45 \mathrm{~W} / \mathrm{m}^{2}$. Such discrepancies cannot be neglected in the calculation of thermal characteristics of airships.

\section{Conclusions}

(1) The simulation results showed little difference when using the five internal natural convection equations to calculate the thermal characteristics of the stratospheric airship-particularly in daytime when the ambient parameters change drastically, which is counterintuitive. The difference of helium temperature calculated by the different natural convection equations was less than $4 \mathrm{~K}$, which can be ignored in engineering

(2) The thermal characteristics of the airship calculated by different external forced convection equations were quite different. The difference of the calculated helium temperatures was approximately $19 \mathrm{~K}$, and that of the calculated volumes was approximately $19,000 \mathrm{~m}^{3}$ (approximately $5 \%$ of the total volume). The maximum difference in the calculated envelope heat fluxes of external forced convection reached $65 \mathrm{~W} / \mathrm{m}^{2}$. For the five external forced convection equations, the calculation results of equations (vi), (viii), and (x) were similar when applied to the ellipsoid model. However, few heat transfer equations would be suitable for the calculation of forced convection pertaining to large ellipsoidal and double-ellipsoidal airships. Further research should focus on a forced convection equation for large ellipsoidal models with higher accuracy and wider application

\section{Nomenclature}

A: $\quad$ Contact area between the helium gasbags $\left(\mathrm{m}^{2}\right)$

c: $\quad$ Specific heat $(\mathrm{J} /(\mathrm{kg} \cdot \mathrm{K}))$

$h_{\mathrm{CI}}$ : Heat transfer coefficient of internal convection $\left(\mathrm{W} /\left(\mathrm{m}^{2} \cdot \mathrm{K}\right)\right)$

$h_{\mathrm{CE}}$ : Heat transfer coefficient of external convection $\left(\mathrm{W} /\left(\mathrm{m}^{2} \cdot \mathrm{K}\right)\right)$

$I_{\mathrm{DN}}: \quad$ Normal direct solar intensity $\left(\mathrm{W} / \mathrm{m}^{2}\right)$

$I_{\mathrm{S}}: \quad$ Diffuse solar radiation intensity $\left(\mathrm{W} / \mathrm{m}^{2}\right)$

$I_{\mathrm{R}}: \quad$ Ground reflection radiation $\left(\mathrm{W} / \mathrm{m}^{2}\right)$

$L: \quad$ Characteristic length $(\mathrm{m})$

$m: \quad$ Mass of helium $(\mathrm{kg})$

$m_{\mathrm{s}}$ : $\quad$ Mass per square of envelope $\left(\mathrm{kg} / \mathrm{m}^{2}\right)$

Nu: $\quad$ Nusselt number

$P: \quad$ Atmospheric pressure $(\mathrm{Pa})$

$Q_{21}, Q_{12}$ : Heat transfer between the main and additional helium gasbags (W)

$Q_{\mathrm{CI}}$ : $\quad$ Convective heat transfer from the envelope (W)

$\alpha_{\mathrm{e}}$ : $\quad$ Solar absorptivity of envelope

$\beta$ : $\quad$ Angle between the triangle normal vector and solar vector ( $\mathrm{rad})$

$\varepsilon: \quad$ Envelope emissivity

$\theta$ : The angle between the normal vector pointing inside and vertical vector

$\lambda: \quad$ Thermal conductivity of envelope $(\mathrm{W} /(\mathrm{m} \cdot \mathrm{K}))$

$q_{\mathrm{D}, i}: \quad$ Heat flux of direct solar radiation $\left(\mathrm{W} / \mathrm{m}^{2}\right)$

$q_{\mathrm{S}, i}: \quad$ Heat flux of diffuse solar radiation $\left(\mathrm{W} / \mathrm{m}^{2}\right)$

$q_{\mathrm{R}, i}: \quad$ Reflected heat flux $\left(\mathrm{W} / \mathrm{m}^{2}\right)$

$q_{\mathrm{IRS}, i}: \quad$ Heat flux of sky long wave radiation $\left(\mathrm{W} / \mathrm{m}^{2}\right)$

$q_{\mathrm{IRG}, i}: \quad$ Heat flux of ground long wave radiation $\left(\mathrm{W} / \mathrm{m}^{2}\right)$

$q_{\mathrm{IRE}, i}: \quad$ Heat flux of internal envelope radiation $\left(\mathrm{W} / \mathrm{m}^{2}\right)$

$q_{\mathrm{CE}, i}: \quad$ Heat flux of external convection $\left(\mathrm{W} / \mathrm{m}^{2}\right)$

$q_{\mathrm{CI}, i}: \quad$ Heat flux of internal free convection $\left(\mathrm{W} / \mathrm{m}^{2}\right)$

Ra: $\quad$ Rayleigh number

$T: \quad$ Temperature $(\mathrm{K})$

$V: \quad$ Volume of helium gasbag $\left(\mathrm{m}^{3}\right)$

$x: \quad$ Envelope thickness between the gasbags (m)

$X_{i, s}: \quad$ Sky angle (rad)

$X_{i, g}: \quad$ Ground angle ( $\left.\mathrm{rad}\right)$

$\tau$ : $\quad$ Coefficient of atmospheric transparency

$\varepsilon_{\mathrm{s}}$ : $\quad$ Equivalent long-wave radiation emissivity

$\varepsilon_{\mathrm{g}}: \quad$ Ground emissivity

$\sigma: \quad$ Stefan-Boltzmann constant $\left(5.67 \times 10^{-8} \mathrm{~W} /\left(\mathrm{m}^{2} \mathrm{~K}\right)\right)$.

\section{Subscripts}

$i$ : Envelope element number

1: Main helium gasbag 
2: Additional helium gasbag

He: Helium

g: Ground

a: Atmosphere.

\section{Data Availability}

The metadata used to support the findings of this study are available from the corresponding author upon request.

\section{Conflicts of Interest}

The authors declare that there is no conflict of interest regarding the publication of this paper.

\section{Authors' Contributions}

Tong Zhang conceived and supervised all aspects of the study. Shanshan Gen drafted the manuscript. Xin Mu Jiamin, Jiamin Chen, and Junyi Wang assisted with data interpretation and figure plotting. Zan Wu edited the manuscript. All authors commented on the manuscript draft and approved the submission.

\section{Acknowledgments}

This work was supported by the Aeronautical Science Foundation of China (Grant No. 2017ZD10002) and the Priority Academic Program Development of Jiangsu Higher Education Institutions.

\section{References}

[1] D. Zhao, D. Liu, K. Sun, G. Tao, M. Zhu, and Z. Wu, "Research status, technical difficulties and development trend of stratospheric airship," Acta Aeronautica Et Astronautica Sinica, vol. 37, pp. 45-56, 2016.

[2] J. Wu, X. Fang, Z. Wang et al., "Thermal modeling of stratospheric airships," Progress in Aerospace Sciences, vol. 75, pp. 26-37, 2015.

[3] H. Shi, B. Song, Q. Yao, and X. I. Cao, "Thermal performance of stratospheric airships during ascent and descent," Journal of Thermophysics and Heat Transfer, vol. 23, no. 4, pp. 816-821, 2009.

[4] Z. Zheng and L. Xie, "Finite-time path following control for a stratospheric airship with input saturation and error constraint," International Journal of Control, vol. 92, no. 2, pp. 368-393, 2017.

[5] T. Chen, M. Zhu, and Z. Zheng, "Asymmetric errorconstrained path-following control of a stratospheric airship with disturbances and actuator saturation," Mechanical Systems and Signal Processing, vol. 119, pp. 501-522, 2019.

[6] C. Xiao, Y. Wang, P. Zhou, and D. Duan, "Adaptive sliding mode stabilization and positioning control for a multivectored thrust airship with input saturation considered," Transactions of the Institute of Measurement and Control, vol. 40, no. 15, pp. 4208-4219, 2018.

[7] L. Zhang, J. Li, J. Meng, H. Du, M. Lv, and W. Zhu, “Thermal performance analysis of a high-altitude solar-powered hybrid airship," Renewable Energy, vol. 125, pp. 890-906, 2018.
[8] D. Zhao, D. Liu, and M. Zhu, "A surrogate model for thermal characteristics of stratospheric airship," Advances in Space Research, vol. 61, no. 12, pp. 2989-3001, 2018.

[9] E. R. Eckert and T. W. Jackson, Analysis of turbulent freeconvection boundary layer on flat panel, National Aeronautics and Space Administration, Washington, DC, USA, 1950.

[10] F. J. Bayley, "An analysis of turbulent free-convection heattransfer," Proceedings of the Institution of Mechanical Engineers, vol. 169, no. 1, pp. 361-370, 1955.

[11] J. A. Clark, "Cryogenic heat transfer," Advances in Heat Transfer, vol. 5, pp. 325-517, 1969.

[12] W. M. Rohsenow, Handbook of Heat Transfer Fundamenta, McGraw-Hill, New York, NY, USA, 1973.

[13] L. A. Carlson and W. J. Horn, "New thermal and trajectory model for high-altitude balloons," Journal of Aircraft, vol. 20, no. 6, pp. 500-507, 1983.

[14] A. L. Morris, Scientific Ballooning Handbook. NCAR Technical Note, NCAR-TN-99, National Center for Atmospheric Research, Boulder, CO, USA, 1975.

[15] F. P. Incropera and D. P. De Witt, Fundamentals of Heat and Mass Transfer, John Wiley \& Sons, New York, NY, USA, 4th edition, 1996.

[16] J. P. Holman, Heat Transfer, Mc Graw-Hill Book Co., 1986.

[17] F. Kreith, The CRC Handbook of Thermal Engineering, CRC Press LLC, 2000.

[18] N. Kishore and S. Gu, "Momentum and heat transfer phenomena of spheroid particles at moderate Reynolds and Prandtl numbers," International Journal of Heat and Mass Transfer, vol. 54, no. 11-12, pp. 2595-2601, 2011.

[19] A. Richter and P. A. Nikrityuk, "Drag forces and heat transfer coefficients for spherical, cuboidal and ellipsoidal particles in cross flow at sub-critical Reynolds numbers," International Journal of Heat and Mass Transfer, vol. 55, no. 4, pp. 13431354, 2012.

[20] Q. Dai, X. Fang, and Y. Xu, "Numerical study of forced convective heat transfer around a spherical aerostat," Advances in Space Research, vol. 52, no. 12, pp. 2199-2203, 2013.

[21] Q. Dai and X. Fang, "Numerical study of forced convective heat transfer around airships," Advances in Space Research, vol. 57, no. 3, pp. 776-781, 2016.

[22] L. M. Jiji, Heat Convection. Second Edition, Scientific Publishing Services Pvt. Ltd., Chennai, India, 2009.

[23] H. Shi, S. Geng, and X. Qian, "Thermodynamics analysis of a stratospheric airship with hovering capability," Applied Thermal Engineering, vol. 146, pp. 600-607, 2019.

[24] F. Kreith and J. F. Kreider, Numerical Prediction of the Performance of High Altitude Balloons, Atmospheric Technology Division, National Center for Atmospheric Research, 1974.

[25] C. Y. Warner and V. S. Arpaci, "An experimental investigation of turbulent natural convection in air at low pressure along a vertical heated flat plate," International Journal of Heat and Mass Transfer, vol. 11, no. 3, pp. 397-406, 1968.

[26] R. E. Farley, "Balloon Ascent: 3-D simulation tool for the ascent and float of high-altitude balloons," in AIAA 5th ATIO and16th Lighter-Than-Air Sys Tech. and Balloon Systems Conferences, Arlington, VA, USA, September 2005.

[27] X. Li, X. Fang, and Q. Dai, "Research on thermal characteristics of photovoltaic array of stratospheric airship," Journal of Aircraft, vol. 48, no. 4, pp. 1380-1386, 2011.

[28] X. L. Xia, D. F. Li, C. Sun, and L. M. Ruan, "Transient thermal behavior of stratospheric balloons at float conditions," 
Advances in Space Research, vol. 46, no. 9, pp. 1184-1190, 2010.

[29] H. Zhang, X. Fang, and Q. Dai, "Investigation on internal natural convection of stratospheric airship," Journal of Astronautics, vol. 37, pp. 879-886, 2016.

[30] S. Whitaker, "Forced convection heat transfer correlations for flow in pipes, past flat plates, single cylinders, single spheres, and for flow in packed beds and tube bundles," AIChE Journal, vol. 18, no. 2, pp. 361-371, 1972.

[31] K. Harada, K. Eguchi, M. Sano, and S. Sasa, "Experimental study of thermal modeling for stratospheric platform airship," in AIAA's 3rd Annual Aviation Technology, Integration, and Operations (ATIO) Forum, Denver, CO, USA, November 2003. 


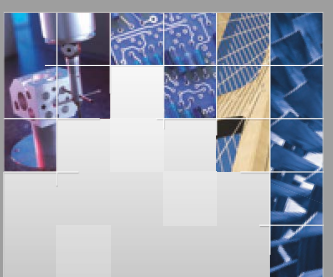

\section{Enfincering}
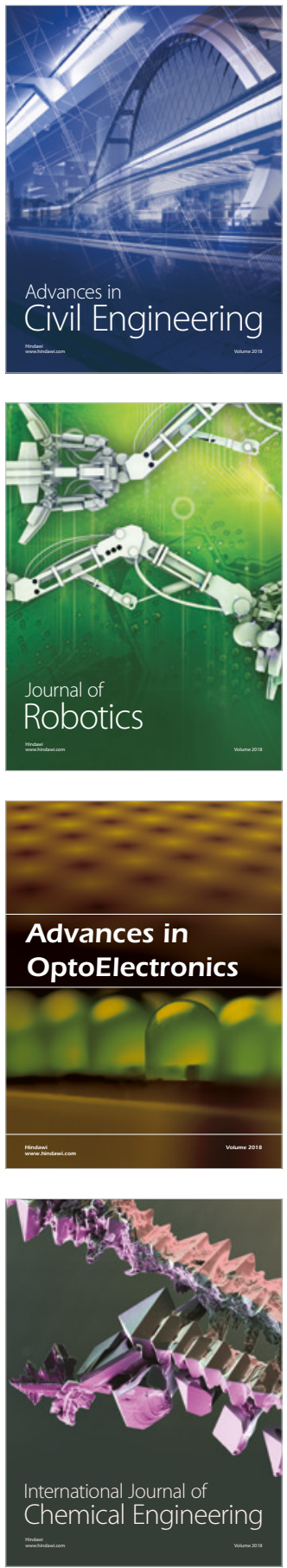

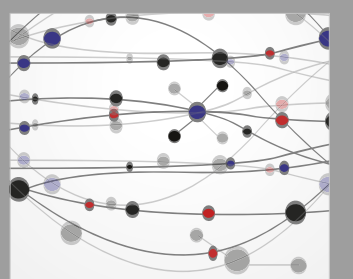

\section{Rotating \\ Machinery}

The Scientific World Journal

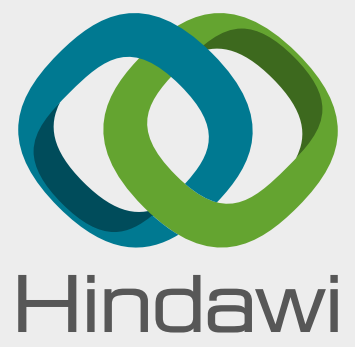

Submit your manuscripts at

www.hindawi.com
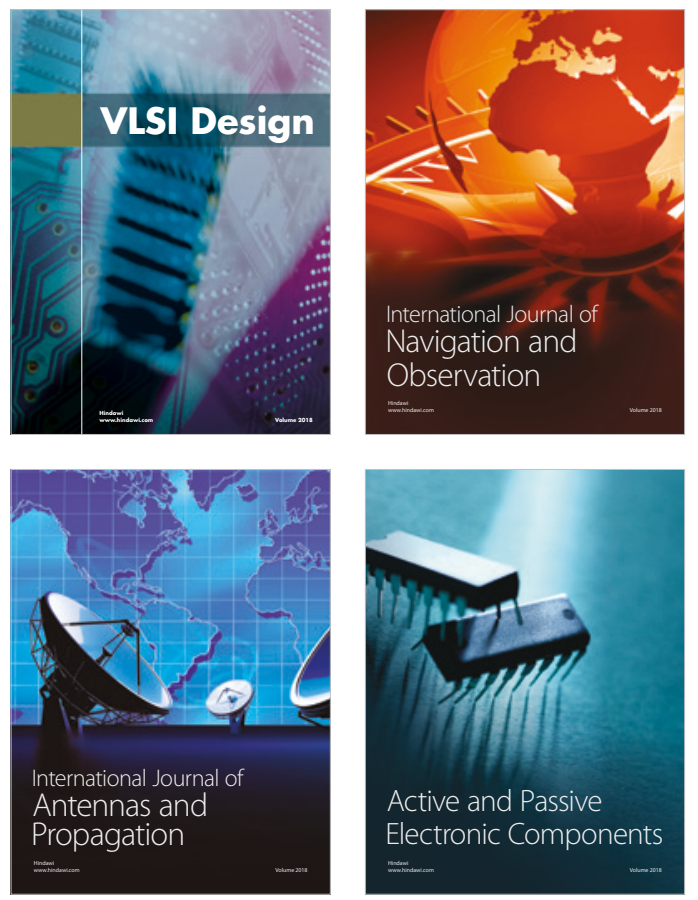
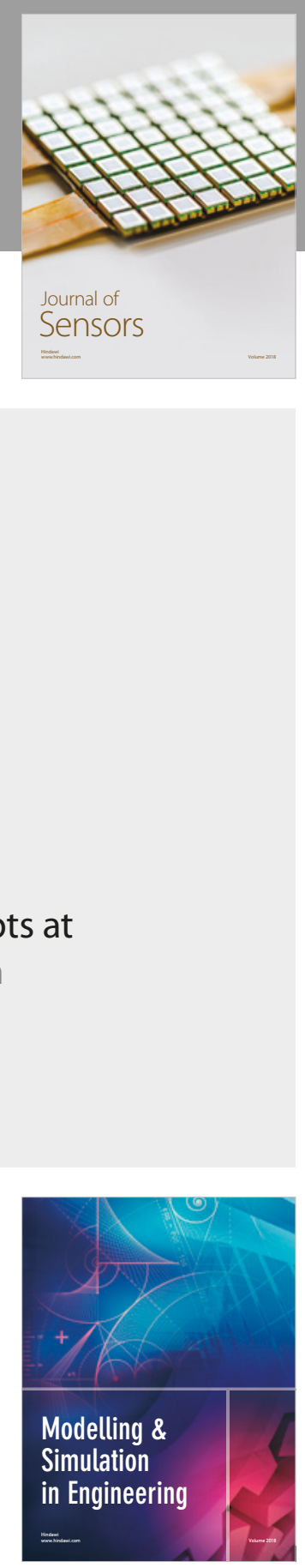

\section{Advances \\ Multimedia}
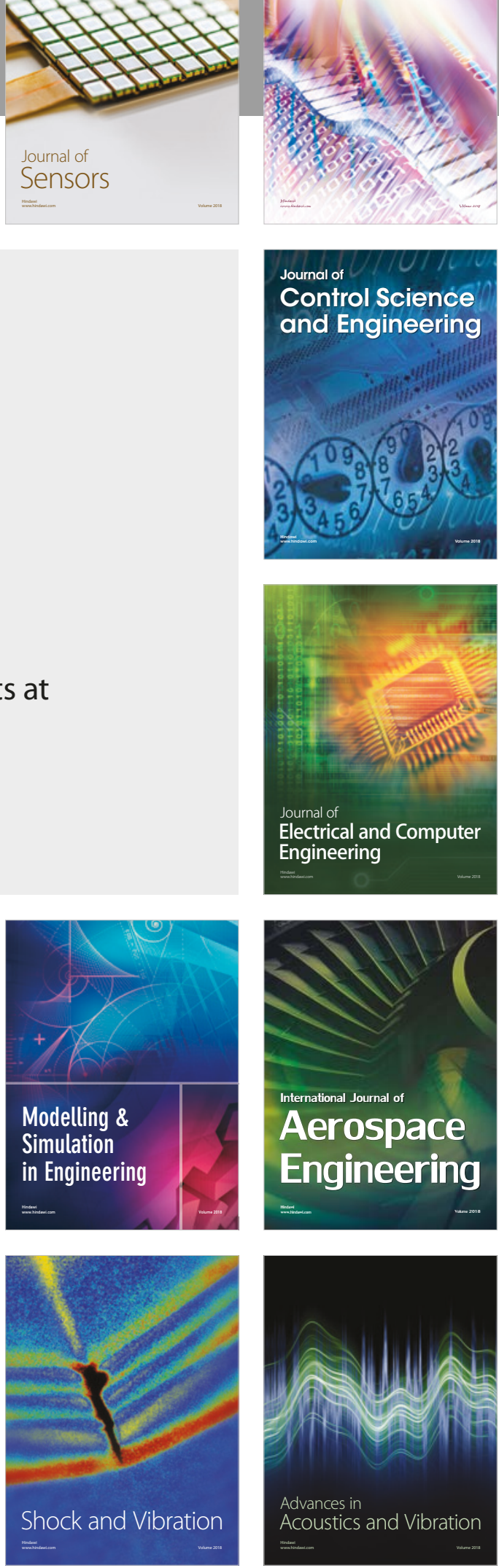